\title{
CLUSTER FOSTER CARE: A PANACEA FOR THE CARE OF CHILDREN IN THE ERA OF HIV/AIDS OR AN MCQ? ${ }^{1}$
}

\section{Jacqui Gallinetti, Julia Sloth-Nielsen}

\section{INTRODUCTION}

The ravages wrought by HIV/AIDS on child-care arrangements in the African context are well documented (Richter \& Sherr, 2009; Sloth-Nielsen \& Mezmur, 2008; Tsegaye, 2007; sources cited there). Notably, these constitute the breakdown of traditional kinship structures which would ordinarily have accommodated orphans and other vulnerable children, a decrease in the capacity of existing extended family structures to care for the numbers of children requiring alternative care, and the emergence of child-headed households. The topic of child-headed households, too, has emerged as a key concept in international child rights law (Couzens \& Zaal, 2009; Sloth-Nielsen, 2004; Sloth-Nielsen in Skelton \& Davel, 2010; UN Committee on the Rights of the Child (UNCROC), General Comment No. 3 on HIV/AIDS and the rights of the child, 2003), and this phenomenon has been directly related to the onset of the pandemic.

This article is written against the backdrop that, in the absence of widespread institutional care, models for absorbing children deprived of a family environment constitute a state obligation under international treaties (the UN Convention on the Rights of the Child (CRC) and the African Charter on the Rights and Welfare of the Child (ACRWC)) as well as South African constitutional law. It must be noted that this article is limited to an analysis of existing law and policy as opposed to providing empirical evidence regarding the potential efficacy or otherwise of cluster foster care as an option for South Africa. Such studies will only be viable once the Children's Act has been in operation for some time.

\section{CONSTITUTIONAL PROVISIONS RELEVANT TO CLUSTER FOSTER CARE}

The relevance of the Constitution to cluster foster care is to be found primarily in Section 28(1)(b), providing for the child's rights to family care, or to alternative care in the absence of a family environment. By judicial analogy, one would have to have regard to section 28(1)(c), providing for the children's rights to shelter, basic nutrition, basic health care services and social services, insofar as the Constitutional Court opined in Government of the Republic of South Africa and Others $v$ Grootboom and Others (2001) that the scope and ambit of the right in section 28(1)(c) entailed a primary obligation upon parents and families to provide for the socio-economic rights of children; however, the various aspects of the child's care entitlements in section 28(1)(c) would fall to the state to implement when children lack family care - either because of removal from their families at the behest of the state, or where children for other reasons lack a family environment (e.g. because of death) (Gallinetti \& Loffell, 2010). Friedman and Pantazis (2008) note further that the reference to parental care in section 28(1)(b) must be read to refer widely to natural parents, adoptive parents, foster parents and stepparents. By implication, however, care in a cluster foster care setting is not yet included amongst the options listed by them.

It is contended that the creation (in formal legal terms) of cluster foster care as an alternative care option via the Children's Act can be typified as one state response to the obligation cast by sections 28(1)(b) and (c) in the face of the HIV/AIDS pandemic (SALRC, 2002). It is

\footnotetext{
${ }^{1}$ Multiple choice question.
} 
incontrovertible that states in HIV affected countries are searching for innovative responses to the care of children affected by the epidemic. It remains, however, to explore the contours of this model and to explore its theoretical basis. Whether cluster foster care is in fact a model, or whether it is a programme or a policy (or none of these!), is the (multiple choice) question we seek to answer.

\section{CLUSTER FOSTER CARE UNDER THE SOUTH AFRICAN CHILDREN'S ACT 38 OF 2005 (AS AMENDED) ${ }^{2}$}

\section{Definitional issues}

Cluster foster care is located as part of the chapter - Chapter 12 - headed "Foster Care". The concept is defined as including "the reception of children into a cluster foster care scheme registered by a provincial department of social development", a definition which, while being internally coherent, does not provide any indication of what the contents/parameters/contours of such a scheme might be. Nor does the definition of "cluster foster care scheme" (section 1) provide any further useful detail: "a cluster foster care scheme is a scheme managed by a nonprofit organization and registered with the provincial department of social development for this purpose". At this point the only clue provided is that "foster care includes foster care in a registered cluster foster care scheme and foster care with a foster parent", which suggests that cluster foster care must resort within the overall conception or definitional parameters of foster care itself. Moreover, this conclusion is supported by the definition of "foster parent", which "includes an active member of an organisation operating a cluster foster care scheme who has been assigned responsibility for a foster child" (also section 1 of the Act). At base, the essence of foster care is therefore internally circumscribed, in limited fashion, in section 180, which refers to "the care of a child as described in section 180(1)" (i.e. by a person who is not the parent or guardian and which placement is a result of an order of a children's court). So we do know that cluster foster care relates to the care of a child, and by persons who are not parents or guardians, and after placement by a children's court!

This conclusion is bolstered by the definition of a foster parent, which "includes an active member of an organisation operating a cluster foster care scheme and who has been assigned responsibility for the foster care of the child" (see, too, section 1). An active member is not, however, defined and thus the outward manifestation of such a scheme remains elusive. Lest it be thought that these definitional difficulties are esoteric or highbrow, it must be born in mind that significant legal consequences might flow from the ascription of the status of cluster foster care scheme or cluster foster care parent, not the least of which is the question of the foster care grant, any other potential state subsidies or benefits, and all the duties and responsibilities of alternative care of children (as provided for in Chapter 11 of the Act). It may be of cardinal importance to determine whether a care-giver can legally be classified as a foster parent for the

\footnotetext{
${ }^{2}$ The new children's legislation in South Africa has been developed in various stages and is comprised of a number of different components. The principal Act 38 of 2005 was supplemented in 2007 by the Children's Amendment Act 41 of 2007. The "spilt" was caused by the national and provincial competencies affected by the various chapters, and the concomitant need for different legislative processes under the Constitution. Neither the principal Act nor the Amendment Act are fully promulgated yet, although certain chapters of the principal Act came into operation on 1 July 2007. In addition, a set of regulations has been developed and these are (at the time of writing) being finalised. Once the principal Act is promulgated, the provisions of the Amendment Act will form part thereof and only one piece of legislation will be in operation, namely the Children's Act 38 of 2005 and its regulations. The chapter discussed in the body of this article, Chapter 12 (Foster Care), falls into the Children's Amendment Bill 41 of 2007 as a concurrent provincial and national competency.
} 
purposes of receiving a state foster care grant, as opposed to whether the scheme (as the legal organ designated by the court) bears the primary legal duty for care of the child and hence looks at first glance to be the likely recipient of the state grant. This distinction may, in turn, become acute were disputes to arise between the care-giver and the scheme, including disputes about the uses to which any state aid might have been put. The spectre of schemes raking off a "top slice" for their own running costs from monies intended for the care of children has also been raised as a concern: in consequence, the legal designations related to cluster foster care are of more than academic interest. ${ }^{3}$

\section{Operational issues}

The Act is not totally silent on the substance of cluster foster care (in contrast to definitional issues). Section 183 speaks to the question of management of cluster foster care schemes and requires, first, that management be effected by a registered non-profit organisation, that such organisation in addition meet certain prescribed requirements and be approved for providing cluster foster care by the provincial department of social development and that, second, the scheme (as distinct from the non-profit organisation) must comply with prescribed requirements and also be registered with the provincial department. That the non-profit organisation (NPO) and the cluster foster care scheme may (must!) have independent legal status from one another (even if the one - the NPO - is the driver of the other - the scheme), seems to be a necessary implication of section 183. The Act does not envisage the one without the other, put differently. A standard scenario could see an established faith-based provider of social services - XYZ church - registering cluster foster schemes in several parishes in different geographical areas where it is active. Although the overall management must be with the (national[?]) organization registered under the NPO Act, provincial departments must oversee the registration of the schemes within their area of jurisdiction and monitor their functioning. (At present, there does not seem to be a mechanism for inter-provincial coordination of these tasks.)

\section{Finding better clarification through the Regulations?}

It is to the draft Regulations, therefore, that one must turn for greater conceptual clarification of the cluster foster care concept. At the outset it must be pointed out that the authors were integrally involved in the drafting of these draft Regulations in the initial phases and that some comments below are drawn from this experience.

Regulations are by definition delegated legislation (Sloth-Nielsen, 2007); they elaborate the provisions of the principal legislation where mandated by that legislation. A key requirement is that the delegated legislation proceed only as far as the principal law allows, for fear of being ultra vires (beyond the powers of the delegation). The Regulations can by definition not introduce new material, contradict the principal Act, correct errors, or contravene the rules of legislative drafting requiring certainty, reasonableness and clarity. Moreover, the standards of the Constitution prevail too - especially those in relation to equality, proportionality and dignity.

A principal driving factor behind the formulation of the draft Regulations (as initially proposed) related to the need to distinguish the (legitimate) grouping of children in cluster

\footnotetext{
${ }^{3}$ The fear has been raised anecdotally that involvement in cluster foster care might be used as a pretext for avoiding waiting lists for housing, or "queue jumping" for other social benefits. Again, legal certainty might be a prerequisite to proper regulation in order to minimise these risks.
} 
foster care from the (illegitimate) mushrooming of unregistered children's homes, many of which have the outward appearance of a form of foster care. Such facilities, in practice, range from what have been regarded as bona fide operations, which simply lack the technical adherence to the departmental norms and standards prescribed for institutional care to enable them to comply formally with the existing requirement for registration of facilities; to less savoury profit centres, cashing in on the availability of state grants for children, especially where the foster grant (payable in much larger amounts than the child support grant) is concerned. The typical shape and form of these unregistered facilities is that they derive their financial benefit through the conglomeration of foster care grants for the individual children in their care, and where multiple "foster carers" each having been appointed in respect of up to six children, reside (or work?) at the same premises.

The Home Truths Study (Meintjies, Moses, Berry \& Mapane, 2007) in four provinces is one recent study which aimed to alert policy makers to this phenomenon. The authors found that the mechanisms applied by those establishing homes but not wanting or able to obtain official registration as a Children's Home involved creative - and somewhat unorthodox - use of existing foster care and private place of safety provisions. The law provides for individuals registered with the State as an emergency parent/private place of safety or foster parent to have up to a maximum of six children placed in their temporary care. Eight of the homes that participated in this study made use of these legislative provisions, placing children in the emergency or foster care of their (employed) care-workers. The approach diverges from the strict application of the law which envisages emergency and foster parents to be caring for children in their own households, and to take full responsibility for children 24 hours a day. In many of the applications documented in this study however, groups of children - though registered in the name of an individual - were cared for by shift-working care-workers, or by housemothers who were present in a more full-time capacity but who were employed by an organisation. (Meintjes et al., 2007:35).

Unregistered children's homes are by definition unregulated and therefore potential sites for violations of children's rights, hence the need for policy and the law to provide for alternatives to institutional care (children's homes) that mirror more closely a private home setting than is currently the case, as well as ensuring appropriate standards where a number of children are accommodated together in a group home setting. ${ }^{4}$

The draft Regulations therefore set a series of requirements for cluster foster care for compliance, which at the same time purport to define and illuminate the contours of cluster foster care as a legally founded (and as a socially grounded) alternative care option. Some requirements established by the draft Regulations relate to the management standards with which the organisation managing or operating a cluster foster care scheme must comply (e.g. audited annual reports; employment of one social worker for every 50 children; prohibition on the employment of active members of the scheme (to cite but three requirements, italics

\footnotetext{
${ }^{4}$ Hence it is argued that cluster foster care was always perceived as an extended foster care placement option (SALRC, 2002:217-218). The concern to ensure that cluster foster care was not a disguise for an unregistered institutional facility was a later development and a by-product of the growing extension in practice of foster care during the period after publication of the SALRC Report and the adoption of the Act. This understanding is reinforced by the SALRC discussion of cluster foster care within a broader concept of collective foster care. Institutional care, whether it is institutional care in group or in cottage-style accommodation, is discussed separately in a different chapter. There is no indication of "cross pollination" between the two concepts in initial documents.
} 
inserted)). Furthermore, the draft Regulations then detail requirements with which a scheme must comply (no more than 6 foster children may be placed with an active member of the scheme or a couple attached to the scheme, and no more than 3 active members may be resident at the same physical address; the scheme must monitor how the active member utilises any foster grant received on behalf of a foster child under the care of the scheme, which in turn, and crucially, implies that the grant is received directly by each active member and not centrally by the scheme itself). Finally, the draft Regulations also provide a modus operandi for the functioning of the cluster foster care scheme, including requiring a care plan for each child, the provision of support, mentoring and assistance to active members, and the requirement that children in the care of the scheme (note: not the active members!) be assisted to access health and educational services.

It has been noted that, seen as a whole, the draft Regulations suggest that cluster foster care schemes not only are required to provide programmes and support for the children placed in their care, but also to active members of the organization to whom the responsibility of providing care for the children has been assigned (Gallinetti \& Loffell, 2010 (forthcoming)). This emphasis on support for active members of the scheme, coupled with a prohibition on the employment of members, underscores the difference between a children's home with staff, and an understanding of cluster foster care as a scheme comprising a "grouping of care-givers who are linked together to provide mutual support in the care of a number of children, and who receive some form of external support and monitoring" (SALRC, 2001 Discussion Paper, par 17.3.1.5). Meintijes et al. (2007), referring to an earlier version of the Children's Act before the text was finalised in Parliament, note that:

Cluster foster care provisions as they currently stand in the Bill adapt foster care from being conceptualised as a family- or household-based intervention, to one which more closely approximates a residential care-type setting. Despite this fact, cluster foster-care schemes are not subject to the same requirements as residential care facilities. While not overtly mentioned in the Bill, it is understood that cluster foster-care schemes are envisaged as one of the approaches to addressing the anticipated increase in child-care burden resulting from the AIDS epidemic. (Meintjies et al., 2007:14)

It can be concluded that the draft Regulations, seen together with the paucity of a descriptive or conceptual framework within which cluster foster care can resort in the Act itself, merely regulate compliance formalities, without prescribing, describing or clarifying the nature of this type of alternative care in a clearly articulated way. They nevertheless give key clues as to what foster care is not. This leads to the next set of questions.

\section{CLUSTER FOSTER CARE: A MODEL, A PROGRAMME OR A POLICY?}

In 1998 the South African Law Reform Commission noted that "despite much rhetoric, examples of successful and sustainable community care projects are hard to find" (SALRC, 2001 Discussion Paper par 17.3.1.1). However, the situation concerning cluster foster care in practice, for all its evident commendability in international circles (Dambach, 2009), is perhaps not very different a decade later. Indeed, during consultations on the drafting of the Regulations, it was clear that understanding of the concept varied enormously, with a frequently cited model being the well-known group home/children's village model, which is to others (including the authors) not cluster foster care at all, but an architecturally different design for institutional care. 
This leads inevitably to the question as to whether cluster foster care can indeed be described independently as a model for collective foster care at all? Or, by way of contrast, is cluster foster care simply a collective name for a series of programmes, each of which can differ dramatically, but none of which fully complies with the idea that cluster foster care can be seen as an independent empirical entity?

A parallel can be drawn with the child justice field, where diversion programmes have a solid history in praxis in South Africa. As has been eloquently detailed (Dawes \& Van Der Merwe, 2005; Gallinetti, 2004; Gallinetti, Kassan \& Ehlers , 2006; Skelton, 2005; Sloth-Nielsen, 2001), diversion programmes for channelling children in conflict with the law into productive activities and away from formal criminal proceedings comprise a multiplicity of theoretical and practical components designed to intervene behaviourally to shift a child's response away from criminal activities and to prevent re-offending. Offered by different service providers, with different skills and objectives, and at differing levels of "intensity" (short-term to longer-term contacts), subjected to fairly rigorous evaluation and research (Dawes \& Van Der Merwe, 2005; Muntingh, 1995, 2001; Steyn, 2005; Wood, 2003) and ultimately coalescing into a comprehensive set of minimum standards for diversion (Department of Social Development, 2007), this arena of social service delivery continues to display growth, innovation and a complex array of characteristics which defy a unitary understanding or simplistic abstract depiction. Rather, diversion programmes, which are related chiefly through the process of taking children away from formal court processes, usually achieve the same objectives and purposes (Child Justice Act, 75 of 2008, s 1 and s 51), but can take on many different shapes and forms using different activities and underpinned by different theories of child development and behaviour modification.

Similarly, cluster foster care appears to defy a unitary definition: rather, it seems to be composed of a series of programmes, activities and arrangements catering for specific community settings, organizational structures, active member's involvement and the like. Having said this, experiential knowledge of what diversion is has now provided a generalised definition and common understanding, whereas this is still not the case with cluster foster care. In particular, the confusion regarding the line between institutional care in group homes and cluster foster care continues to dominate practice debates in this sphere. Nevertheless, the requirements that the draft Regulations set for the development of care plans for each child, for mentoring and active assistance to members, and for assistance to children to access health and education services points to cluster foster care being a set of related measures or activities with a long-term aim (Maguire \& Priestley, 1995).

Insofar as a policy is designed to be, amongst other things, forward looking, evidenced-based and outcomes oriented, cluster foster care cannot strictly speaking comply with all the prerequisites for it to represent a credible, substance-based and impact-focused policy, or policytype intervention (Bullock, Mountlord \& Stanley, 2001). While the concept has obvious roots in the desire to innovatively extend the available state-recognised care options in the era of HIV/AIDS and children without parental care, it remains, in our view, too elusive a concept definitionally to qualify as a policy.

\section{CLUSTER FOSTER CARE AND INTERNATIONAL STANDARDS}

The spread of HIV/AIDS and the growth of institutional arrangements (Save the Children, 2009) has prompted the international community to examine more closely state responses to the care and welfare needs of children through institutional care (orphanages, vocational or 
educational training centres, borstals, children's homes and the like). The adoption, on 20 November 2009, of new Guidelines for Alternative Care of Children (A/HRC/11/L.13) by the United Nations signals a new era in the development and regulation of the care of children deprived of a family environment. It is therefore within the framework set by the UN Guidelines that the phenomenon of cluster foster care must be assessed and addressed.

At first blush, despite anecdotal international interest in cluster foster care as a novel approach to the care of children without a family environment (and one which has been touted as being indigenous to Africa), it may be of interest that the Guidelines do not mention cluster foster care by name, although foster care is depicted as a form of formal alternative care arrangement. The Guidelines appear to favour what has, in the South African context (Inter-Ministerial Committee on young People at Risk, 1997), been termed professional foster care, i.e. foster carers selected from a pre-approved pool in each locality, who have been provided with special preparation, support and counselling services before, during and after the placement (Guidelines 118 and 119). The requirements for foster care are further elaborated in Guideline 28(c)(ii), which defines foster care as "placement by a competent authority for the purpose of alternative care in the domestic environment of a family other than the child's own family, that has been selected, qualified, approved and supervised for providing such care". This definition would not exclude cluster foster care, insofar as both envisage care "in the domestic environment of a family"... and the supervision of children living in such alternative care setting. However, a key difference lies in the selection, pre-qualification and prior approval of foster parents, which is absent (at least as a stated requirement) from the South African collective foster care notion discussed here, although pre-selection of potential "active members" is not excluded.

The closest the Guidelines come to the vision of the SALRC in relation to cluster foster care is Guideline 121, which encourages the establishment of associations of foster carers "that can provide mutual support and contribute to practice and policy development". However, that these support and mentoring arrangements are distinct from legal structures is evident from the tenor of other Guidelines contained in the text as a whole. Notably, the Guidelines clarify that legal responsibility for a child in alternative care should be vested with a designated individual or entity "with the legal right and responsibility to make ... decisions in the place of parents..." (Guideline 100).

Thus it can be concluded that while international law and policy do not support cluster foster care directly as a "home grown" form of alternative care, neither do the principles, precepts or guidelines exclude the type of provisions that in South African law now constitute "cluster foster care".

\section{CONCLUSION}

This article has sought to explain "cluster foster care" by reference to fairly traditional social work paradigms, which include models of care, alternative care programmes and policies. A close examination of both the legislation and the practical data available indicates that cluster foster care cannot neatly be categorised as any one of these, partly because the development of

\footnotetext{
${ }^{5}$ It is not implied that persons who are unfit or ineligible may serve either as foster parents or as active members of a cluster foster care scheme, as section 182 of the Act clarifies. However, we assert that there is difference between placing children with listed applicants for foster child, as pertains in some jurisdictions, and bringing together community members looking after children for mutual support and mentoring.
} 
the legal concept has probably preceded its practical application, and partly because the development of the concept was "sidetracked" by the emergence of a plethora of unregistered children's homes during the law-making period. This, in turn, required definitions of the concept to focus particularly on distinguishing cluster foster care from group homes and traditional residential care, as opposed to allowing existing community-based models of collective foster care to dictate the agenda, or to surface as the ideal or prototype. In sum, cluster foster care remains elusive and vague, and will (law and regulations notwithstanding) undoubtedly result in disparate implementation at provincial level.

However, contradictorily, the future may reveal that the seemingly "empty vessel" that cluster care currently is turns out to be the basis for innovation and grassroots development.

\section{REFERENCES}

BULLOCK, H., MOUNTFORD, J. \& STANLEY, R. 2001. Better policy making. London: Centre for Management and Policy Studies.

COUZENS, M. \& ZAAL, N. 2009. Legal recognition for child-headed households: an evaluation of the emerging South African framework. International Journal of Children's Rights, 17(2):299-320.

DAMBACH, M. 2009. UN Guidelines for Alternative Care. Children in Alternative Care Seminar. Cape Town: University of the Western Cape. October 2009.

DAVEL, C. \& SKELTON, A. (eds) 2010. Commentary on the Children's Act ( $2^{\text {nd }}$ ed). Lansdowne: Juta and Co Ltd. (forthcoming)

DAWES, A. \& VAN DER MERWE, A. 2005. The Development of Minimum Standards for Diversion Programmes in the Child Justice System. Cape Town: Human Sciences Research Council.

DEPARTMENT OF SOCIAL DEVELOPMENT. 2007. Minimum norms and standards on diversion. Pretoria: Government Printers.

FRIEDMAN, A. \& PANTAZIS, A. 2008. Children's rights. In: WOOLMAN, S. \& ROUX, T. (eds) Constitutional Law of South Africa ( $2^{\text {nd }}$ ed). Wetton: Juta and Co Ltd.

GALLINETTI, J. 2004. Diversion. In: SLOTH-NIELSEN, J. \& GALLINETTI, J. (eds) Child justice in Africa: a guide to good practice. Cape Town: Community Law Centre.

GALlinetTi, J., KASSAN, D. \& EHLERS, L. (eds) 2006. Child justice in South Africa: children's rights under construction conference report. Cape Town: Open Society Foundation for South Africa \& the Child Justice Alliance.

GALLINETTI, J. \& LOFFELL, J. 2010. Foster care. In: DAVEL, C. \& SKELTON, A. (eds) Commentary on the Children's Act $\left(2^{\text {nd }}\right.$ ed). Lansdowne: Juta and Co Ltd. (forthcoming)

INTER-MINISTERIAL COMMITTEE ON YOUNG PEOPLE AT RISK. 1997. Report on the Pilot Programmes. Cape Town: The Printing Press.

McGUIRE, J. \& PRIESTLEY, P. 1995. Reviewing what works: past, present and future. In: McGUIRE, J. (ed) What works: reducing re-offending: guidelines from research and practice. Chichester: Wiley. 
MEINTJIES, H., MOSES, S., BERRY, L. \& MAPANE, R. 2007. Home truths: the phenomenon of residential care for children in a time of AIDS. Cape Town: Children's Institute, University of Cape Town \& Centre for the Study of AIDS, University of Pretoria.

MUNTINGH, L. (ed) 1995. Perspectives on diversion. Cape Town: NICRO National Office.

MUNTINGH, L 2001. The effectiveness of diversion programmes: a longitudinal evaluation of cases. Cape Town: Nicro.

RICHTER, L. \& SHERR, L. 2009. Family ties: reconstructing the care of vulnerable children: the 'orphan' label doesn't help. HSRC Review, 7(4):28-29.

SAVE THE CHILDREN. 2009. Keeping children out of harmful institutions: why we should be investing in family based care. London: Save the Children.

SKELTON, A. 2005. The influence of the theory and practice of restorative justice in South Africa with special reference to child justice. Pretoria: University of Pretoria. (LLD Thesis)

SLOTH-NIELSEN, J. 2001. The role of international law in juvenile justice reform in South Africa. Cape Town: University of the Western Cape. (LLD Thesis)

SLOTH-NIELSEN, J. 2004. Realising the rights of children growing up in child headed households: a guide to laws, policies and social advocacy. Cape Town: Community Law Centre.

SLOTH-NIELSEN, J. 2007. Protection of children. In: DAVEL, C. \& SKELTON, A. (eds) Commentary on the Children's Act. Lansdowne: Juta and Co Ltd.

SLOTH-NIELSEN, J. 2007. Regulations for the Children's Act: presentation to the Department of Social Development. Pretoria. January 2007.

SLOTH-NIELSEN, J. \& MEZMUR, B. 2008. HIV/AIDS and children's rights in law and policy in Africa: confronting hydra head on. In: SLOTH NIELSEN, J. (ed). Children's Rights in Africa: a legal perspective. Hampshire: Ashgate Publishing.

SLOTH-NIELSEN, J. 2010. Child Protection Part 1 and Part 4. In: DAVEL, C. \& SKELTON, A. (eds) Commentary on the Children's Act $\left(2^{\text {nd }}\right.$ ed). Lansdowne: Juta and Co. Ltd. (forthcoming)

SALRC - South African Law Reform Commission (Project 110) 2001. Discussion Paper 103: review of the Child Care Act. Pretoria: Government Printers.

SALRC - South African Law Reform Commission (Project 110) 2002. Report: review of the Child Care Act. Pretoria: Government Printers.

STEYN, F. 2005. Review of South African innovations in diversion and reintegration of youth at risk. Cape Town: Open Society Foundation for South Africa.

GOVERNMENT OF THE REPUBLIC OF SOUTH AFRICA AND OTHERS V GROOTBOOM AND OTHERS. 2001. (1) SA 46 (CC).

TSEGAYE, S. 2007. HIV/AIDS and the emerging challenge of children heading households: discussion paper. Addis Ababa: The African Child Policy Forum.

UN COMMITTEE ON THE RIGHTS OF THE CHILD. General Comment No. 3. 2003. HIV/AIDS and the rights of the child. CRC/GC/2003/3. 
UNITED NATIONS GUIDELINES FOR ALTERNATIVE CARE OF CHILDREN. 2009. A/HRC/11/L.13.

WOOD, C. 2003. Diversion in South Africa: a review of policy and practice 1990-2003: Occasional Paper 79. Pretoria: Institute for Security Studies.

Dr Jacqui Gallinetti and Prof Julia Sloth-Nielsen, Faculty of Law, University of the Western Cape, Bellville, South Africa. 